\title{
ДОСЛІДЖЕННЯ ПРОЦЕСУ РУЙНУВАННЯ МАТЕРІАЛУ В КАМЕРІ ДРОБЛЕННЯ ВІБРАЦІЙНОЇ ЩОКОВОЇ ДРОБАРКИ
}

\author{
Іван Назаренко, Євген Міщук
}

Київський національний університет будівництва і архітектури

03680, Повітрофрлотський просп. 31, Київ, Україна, e-mail: jmishchuk@gmail.com

\section{RESEARCH PROCESS OF DESTRUCTION OF THE MATERIAL IN THE GRINDING CHAMBER OF THE VIBRATING JAW CRUSHER}

\author{
Ivan Nazarenko, Eugen Mishchuk \\ Kyiv National University of Construction and Architecture \\ 03680, Povitroflotsky Avenue 31, Kyiv, Ukraine, e-mail: jmishchuk@gmail.com
}

\begin{abstract}
АНОТАЦІЯ. Розроблена модель руйнування матеріалу в камері дроблення вібраційної щокової дробарки. Приведені залежності для розрахунку двох напружено-дефрормованих станів матеріалу при його руйнуванні: до утворення тріщини і після утворення тріщини. Дана оцінка процесу руйнування після утворення тріщини в матеріалі.
\end{abstract}

Ключові слова: напружено-деформований стан, еліптичний інтеграл, руйнування.

АННОТАЦИЯ. Разработана модель разрушения материала в камере измельчения вибрационной щековой дробилки. Приведены зависимости для расчета двух напряженно-деформированных состояний материала при его разрушении: до образования трещины и после образования трещины. Дана оценка процесса разрушения после образования трещины в материале.

Ключевые слова: напряженно-деформированное состояние, эллиптический интеграл, разрушение.

ABSTRACT. Purpose. The main purpose of this article is to create a mathematical model that describes the process of destruction in the grinding chamber vibration jaw crusher and that considering the stress-strain state of the material. Methodology of research. In this article used the methods of elasticity and approaches of mathematics. Findings. The calculated values of stresses and displacements taking into account presence cracks in the material. It was established that the main share of energy is spent on elastic deformation and cracking. Are constructed and analyzed the graphic depending of stress on the size cracks, elliptical module and radius $\boldsymbol{R e}-$ search limitations/implications. The calculations did not include the expenses of energy for heating and plastic destruction. Originality/value. Knowledge of the stress-strain state makes it possible to further determine the energy expenses for the destruction of the material in the grinding chamber vibration jaw crusher. Based on the dependences of presented in this paper can be set on the destruction optimal efforts and to design energy efficient machine for the crushing of building materials.

Key words: stress-strain state, elliptic integral, destruction.

\section{ВСТУП}

Руйнування матеріалу в камері дроблення щокової дробарки є складним процесом, на який впливає ряд різноманітних факторів, що мають імовірнісний характер. До цих факторів відносяться форма матеріалу і його міцність, наявність тріщин в матеріалі (розміри тріщини, іiі дислокація відносно прикладеного зусилля та кількість тріщин), розташування самого матеріалу в камері дроблення (обпирання на робочі поверхні машини чи взаємодія з іншими кусками подрібнюваного матеріалу) тощо. Існуючі математичні залежності не повною мірою враховують всі ці фактори, а процес дроб- лення описується складними математичними формулами.

\section{ОГЛЯД ПУБЛІКАЦІЙ}

Відома велика кількість рішень задачі 3 визначення напружено-деформованого стану суцільного матеріалу [16-18]. Проте ці рішення або $є$ складними $\mathrm{i}$ значно об'ємними (в зв'язку з використанням бігармонічних функцій), або не враховують наявність тріщини в тілі матеріалу, що руйнується.

В джерелах [19-21] розглянуто напружено-деформований стан матеріалу, який містить дископодібну тріщину. Отримані рішення є частковими, так як в більшості 
випадків форма тріщини більш схожа на еліпс.

В джерелі [22] розглянуто рішення задачі напружено-деформованого стану матеріалу за наявності в ньому зони розриву. В цьому випадку вирішувалась задача на площині.

Наведені рішення описують напруженодеформований стан тіла в цілому без врахування специфіки робочого процесу в камері дроблення вібраційної щокової дробарки.

\section{МЕТА РОБОТИ}

Метою роботи є розробка математичної моделі, що адекватно описує процес руйнування матеріалу в камері дроблення вібраційної щокової дробарки і рішення задачі 3 визначення напружень та деформацій в матеріалі при його руйнуванні 3 врахуванням зони розриву в матеріалі.

\section{ВИКЛАД ОСНОВНОГО МАТЕРІАЛУ}

При проведенні досліджень прийнято, що матеріал, який підлягає руйнуванню, поводить себе як абсолютно пружне тіло і водночас $\epsilon$ ізотропним. При дробленні матеріалу робочий цикл дробильних щік вібраційної щокової дробарки умовно поділяється на 3 етапи: відхід дробильної щоки і просування матеріалу в напрямку його розвантаження за рахунок сил тяжіння; зближення дробильної щоки і матеріалу, за рахунок чого утворюються зовнішні зони руйнування та накопичуються внутрішні напруження; подальше переміщення дро- бильних щік, стиснення матеріалу та підвищення внутрішніх напружень, наслідком чого є руйнування матеріалу. В даній роботі розглядається третій етап робочого циклу. Таким чином в деякому наближенні за модель процесу руйнування можна взяти статичну модель.

Грунтуючись на гіпотезі Пуанкаре, яка стверджує, що будь-яка тривимірна поверхня $є$ гомеоморфною тривимірній сфері, за узагальнену фізичну модель форми матеріалу була прийнята сфера [1-3].

Зона контакту робочого тіла (матеріалу) 3 робочими поверхнями дробарки (дробильними щоками) обрана 34 можливих моделей (рис.1) [13]: а) контакт по двом точкам; б) контакт по трьом точкам; в) контакт по точці і ділянці; г) контакт по двом ділянкам. Прийнято контакт по двом точкам.

Для визначення витрат енергії на дроблення 3 врахуванням напружено-деформованого стану матеріалу використано метод, запропонований в [4].

3 використанням принципу суперпозиції двох напружених станів матеріалу, а саме НДС тіла без тріщини та НДС в околі тріщини, отримано наступне рівняння:

$$
\mathrm{u}=\mathrm{i}_{1}+\mathrm{j}_{\mathrm{nx}} ; \quad \sigma=\sigma_{\mathrm{x}}+\sigma_{\mathrm{nx}},
$$

де $\mathrm{u}, \sigma$ - загальні переміщення та напруження; $\mathrm{i}_{1}, \sigma_{\mathrm{x}}-$ відповідно переміщення та напруження, що розраховані для тіла без тріщини; $\mathrm{j}_{\mathrm{nx}}, \sigma_{\mathrm{nx}}-$ відповідно переміщення та напруження, що розраховані для тіла 3 тріщиною.

Схема до визначення напруженодеформованого стану матеріалу наведена на рис. 2.

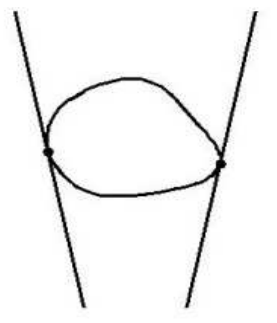

a

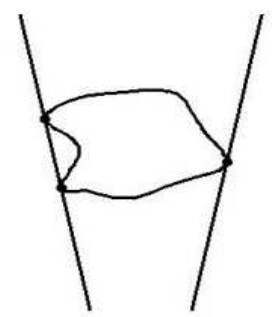

$\delta$

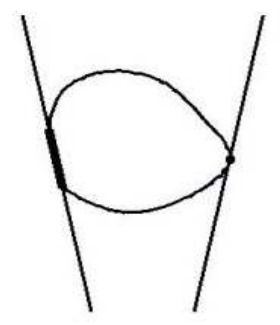

B

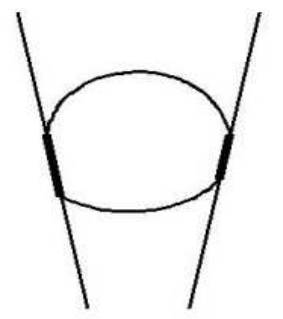

2

Рис. 1. Моделі контакту матеріалу з робочими поверхнями дробарки

Fig.1. Models of the contact of material with work surfaces crusher 


\section{АОСАІАЖЕННЯ ПРОЦЕСУ РУЙНУВАННЯ МАТЕРІААУ В КАМЕРІ АРОБАЕННЯ ВІБРАЦІЙНОЇ ЩОКОВОЇ АРОБАРКИ}

Повний опис напружено-деформованого стану в лінійній теорії пружності (сферичні координати) містить по три рівняння рівноваги, деформацій, напружень та граничні умови на контурі [6-8, 12, 23].

Для розв'язку поставленої задачі використано метод переміщень, в якому основними невідомими є функції переміщень.

Ці функції повинні задовольняти трьом основним умовам:

1) бути гармонічними або бігармонічними функціями;

2) перетворювати рівняння пружної рівноваги тіла в тотожність [8], [23];

3) перетворювати рівняння сумісності на поверхні [7] в тотожність.

Рівняння для функцій переміщення в загальному вигляді [6]:

$$
2 \mathrm{Gu}_{\mathrm{x}}=4(1-v) \chi_{\mathrm{x}}-\frac{\partial \mathrm{M}}{\partial \mathrm{x}_{\mathrm{n}}},
$$

де $\mathrm{M}=\mathrm{x}_{\mathrm{k}} \chi_{\mathrm{x}}+\chi_{0}-$ об' ємні сили; $\mathrm{G}$ - модуль зсуву; $v$ - коефіцієнт Пуассона; $\chi_{\mathrm{x}}, \chi_{0}-$ довільні гармонічні функції; $\mathrm{u}_{\mathrm{x}}-$ переміщення по відповідним координатним осям.

Рішення рівняння (2), без врахування об'ємних сил, зводиться до знаходження гармонічних функцій $\chi_{x}$.
Такими функціями є об'ємні сферичні функції, які в загальному вигляді записуються наступним чином [8], [23]

$$
\begin{aligned}
& \chi=\Sigma\left(A_{n} \times \rho^{n}+B_{n} \times \rho^{-n-1}\right) \times \\
& \times\left(C_{m} \cos [m \times \theta]+D_{m} \times \sin [m * \theta]\right) \times \\
& \times\left(L_{n m} * P_{n m}(\mu)+F_{n m} * Q_{n m}(\mu)\right),
\end{aligned}
$$

де $\mu=\cos [\varphi]$;

$\mathrm{P}_{\mathrm{nm}}(\mu)=\frac{\left(1-\mu^{2}\right)^{\frac{\mathrm{m}}{2}}}{2^{\mathrm{n}} \mathrm{n} !} * \frac{\mathrm{d}^{\mathrm{n}+\mathrm{m}}}{\mathrm{d} \mu^{\mathrm{n}+\mathrm{m}}}\left(\mu^{2}-1\right)^{\mathrm{n}}-$ функція Лежандра першого роду, степені $\mathrm{n}$ та порядку $\mathrm{m} ; \mathrm{Q}_{\mathrm{nm}}(\mu)=\left(1-\mu^{2}\right)^{\frac{\mathrm{m}}{2}} * \frac{\mathrm{d}^{\mathrm{m}} \mathrm{Q}_{\mathrm{n}}(\mu)}{\mathrm{d} \mu^{\mathrm{m}}}-$ функція Лежандра другого роду, степені n та порядку m;

$\mathrm{Q}_{\mathrm{n}}(\mu)=\frac{1}{2} \mathrm{P}_{\mathrm{n}}(\mu) \ln \left[\frac{1+\mu}{1-\mu}\right]-\sum_{\mathrm{k}=1}^{\mathrm{n}} \frac{1}{\mathrm{k}} \mathrm{P}_{\mathrm{k}-1}(\mu) \mathrm{P}_{\mathrm{n}-\mathrm{k}}(\mu)$

- функція Лежандра другого роду;

$\mathrm{P}_{\mathrm{n}}(\mu)=\frac{1}{2^{\mathrm{n}} \mathrm{n} !} * \frac{\mathrm{d}^{\mathrm{n}}}{\mathrm{d} \mu^{\mathrm{n}}}\left(\mu^{2}-1\right)^{\mathrm{n}}-$ функція Лежандра першого роду;

$\mathrm{A}_{\mathrm{n}}, \mathrm{B}_{\mathrm{n}}, \mathrm{C}_{\mathrm{m}}, \mathrm{D}_{\mathrm{m}}, \mathrm{L}_{\mathrm{n}, \mathrm{m}}, \mathrm{F}_{\mathrm{n}, \mathrm{m}}$ - константи.

Розглядається найбільш нетипова умова, за якої n1-n3,m1-m3 різні цілі числа, при цьому $-1<\mu<1$. Для подальших розрахун-

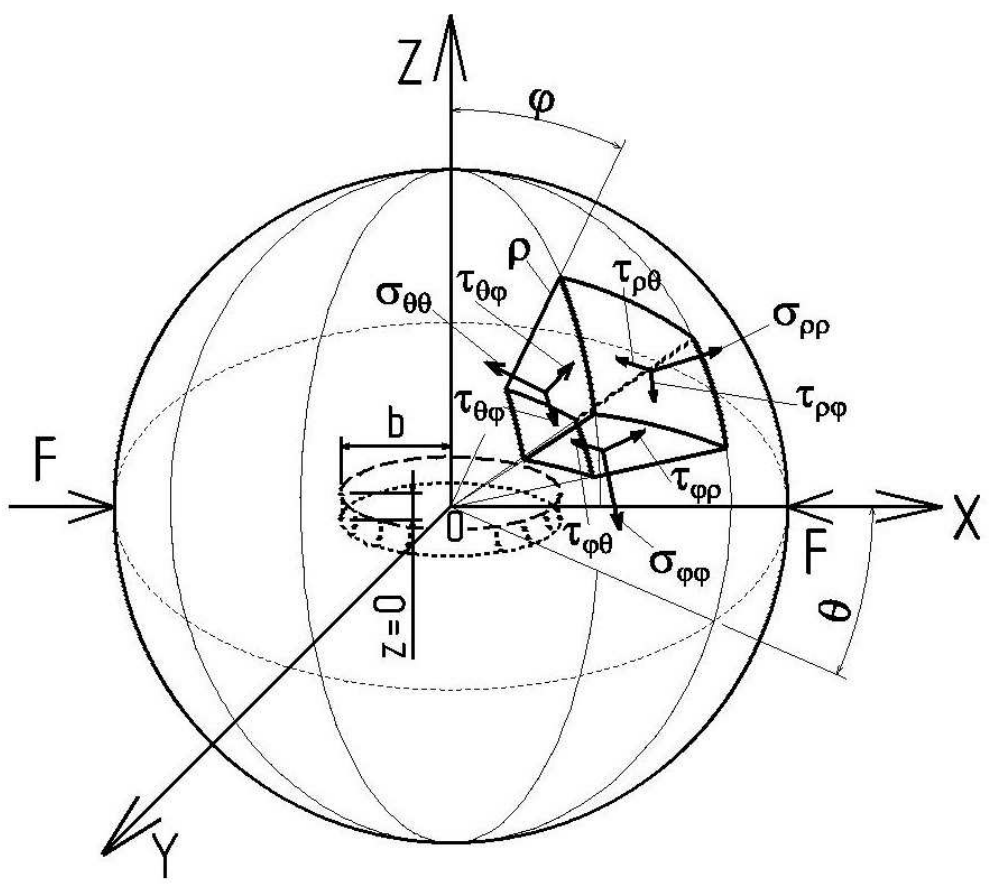

Рис.2. Схема до визначення напружено-деформованого стану при наявності розриву в тілі

Fig.2. The scheme to determine the stress-strain state at presence of the gap in the body 
ків прийнято: $\mathrm{n} 1=4, \mathrm{~m} 1=1 ; \mathrm{n} 2=5, \mathrm{~m} 2=2$; $\mathrm{n} 3=6, \mathrm{~m} 3=3$. Після підстановки (3) в (2), отримуються рівняння для визначення переміщень:

$$
\begin{aligned}
& \mathrm{u}=\left[-\frac{4}{\sqrt{1-\mu^{2}}} \rho^{2} \cos [\theta] \sin [\phi] \times\right. \\
& \times\left(\rho^{9} \mathrm{~A}_{4}+\mathrm{B}_{4}\right)\left(\sin [\theta] \mathrm{H}_{1}+\cos [\theta] \mathrm{M}_{1}\right) \times \\
& \times\left(\left(-32+230 \mu^{2}-210 \mu^{4}+15 \mu \times\right.\right. \\
& \left.\times\left(3-10 \mu^{2}+7 \mu^{4}\right) \log \left[\frac{1+\mu}{1-\mu}\right]\right) \mathrm{F}_{4,1}+ \\
& \left.+30 \mu\left(3-10 \mu^{2}+7 \mu^{4}\right) \mathrm{L}_{4,1}\right)+\frac{4}{\sqrt{1-\mu^{2}}} \times
\end{aligned}
$$$$
\times v \rho^{2} \cos [\theta] \sin [\phi]\left(\rho^{9} \mathrm{~A}_{4}+\mathrm{B}_{4}\right) \times
$$$$
\times\left(\sin [\theta] \mathrm{H}_{1}+\cos [\theta] \mathrm{M}_{1}\right)\left(\left(-32+230 \mu^{2}-\right.\right.
$$$$
-210 \mu^{4}+15 \mu\left(3-10 \mu^{2}+7 \mu^{4}\right) \times
$$$$
\left.\times \log \left[\frac{1+\mu}{1-\mu}\right]\right) F_{4,1}+30 \mu\left(3-10 \mu^{2}+\right.
$$$$
\left.\left.+7 \mu^{4}\right) \mathrm{~L}_{4,1}\right)-\frac{12}{-1+\mu^{2}} \rho \sin [\theta] \sin [\phi] \times
$$$$
\times\left(\rho^{11} \mathrm{~A}_{5}+\mathrm{B}_{5}\right)\left(\sin [2 \theta] \mathrm{H}_{2}+\cos [2 \theta] \times\right.
$$$$
\left.\times \mathrm{M}_{2}\right)\left(\left(64-686 \mu^{2}+1260 \mu^{4}-\right.\right.
$$$$
-630 \mu^{6}+105 \mu\left(-1+\mu^{2}\right)^{2}\left(-1+3 \mu^{2}\right) \times
$$$$
\left.\times \log \left[\frac{1+\mu}{1-\mu}\right]\right) \mathrm{F}_{5,2}+210 \mu\left(-1+\mu^{2}\right)^{2} \times
$$$$
\left.\times\left(-1+3 \mu^{2}\right) \mathrm{L}_{5,2}\right)+\frac{12}{-1+\mu^{2}} v \rho \sin [\theta] \times
$$$$
\times \sin [\phi]\left(\rho^{11} \mathrm{~A}_{5}+\mathrm{B}_{5}\right)\left(\sin [2 \theta] \mathrm{H}_{2}+\right.
$$$$
\left.+\cos [2 \theta] \mathrm{M}_{2}\right)\left(\left(64-686 \mu^{2}+1260 \mu^{4}-\right.\right.
$$$$
-630 \mu^{6}+105 \mu\left(-1+\mu^{2}\right)^{2}\left(-1+3 \mu^{2}\right) \times
$$$$
\left.\times \log \left[\frac{1+\mu}{1-\mu}\right]\right) F_{5,2}+210 \mu\left(-1+\mu^{2}\right)^{2} \times
$$$$
\left.\times\left(-1+3 \mu^{2}\right) \mathrm{L}_{5,2}\right)-\frac{3}{\left(1-\mu^{2}\right)^{3 / 2}} \cos [\phi] \times
$$$$
\times\left(\rho^{13} \mathrm{~A}_{6}+\mathrm{B}_{6}\right)\left(\sin [3 \theta] \mathrm{H}_{3}+\cos [3 \theta] \times\right.
$$$$
\left.\times \mathrm{M}_{3}\right)\left(\left(-512+7326 \mu^{2}-20286 \mu^{4}+\right.\right.
$$$$
+20370 \mu^{6}-6930 \mu^{8}+315 \mu\left(-1+\mu^{2}\right)^{3} \times
$$

$\left.\times\left(-3+11 \mu^{2}\right) \log \left[\frac{1+\mu}{1-\mu}\right]\right) F_{6,3}+630 \mu \times$

$\left.\times\left(-1+\mu^{2}\right)^{3}\left(-3+11 \mu^{2}\right) \mathrm{L}_{6,3}\right] \frac{1}{24 \mathrm{G} \rho^{7}} ;$

$v=\frac{1}{6 G \rho^{6}} \frac{(-1+v)}{-1+\mu^{2}}\left[\sqrt{1-\mu^{2}} \times\right.$

$\times\left[\rho \sin [\theta]\left(\rho^{9} \mathrm{~A}_{4}+\mathrm{B}_{4}\right)\left(\sin [\theta] \mathrm{H}_{1}+\right.\right.$

$\left.+\cos [\theta] \mathrm{M}_{1}\right)\left(\left(-32+230 \mu^{2}-\right.\right.$

$-210 \mu^{4}+15 \mu\left(3-10 \mu^{2}+7 \mu^{4}\right) \times$

$\left.\times \log \left[\frac{1+\mu}{1-\mu}\right]\right) F_{4,1}+30 \mu\left(3-10 \mu^{2}+\right.$

$\left.\left.\left.+7 \mu^{4}\right) \mathrm{L}_{4,1}\right)\right]+\left[3 \cos [\theta]\left(\rho^{11} \mathrm{~A}_{5}+\mathrm{B}_{5}\right) \times\right.$

$\times\left(\sin [2 \theta] \mathrm{H}_{2}+\cos [2 \theta] \mathrm{M}_{2}\right)((64-$

$-686 \mu^{2}+1260 \mu^{4}-630 \mu^{6}+105 \mu \times$

$\left.\times\left(-1+\mu^{2}\right)^{2}\left(-1+3 \mu^{2}\right) \log \left[\frac{1+\mu}{1-\mu}\right]\right) \mathrm{F}_{5,2}+$

$\left.\left.\left.+210 \mu\left(-1+\mu^{2}\right)^{2}\left(-1+3 \mu^{2}\right) \mathrm{L}_{5,2}\right)\right]\right]$;

$\mathrm{w}=\frac{1}{24 \mathrm{G} \rho^{7}}\left[-\frac{1}{\sqrt{1-\mu^{2}}} 4 \rho^{2} \cos [\theta] \times\right.$

$\times \cos [\phi]\left(\rho^{9} \mathrm{~A}_{4}+\mathrm{B}_{4}\right)\left(\sin [\theta] \mathrm{H}_{1}+\right.$ $\left.+\cos [\theta] \mathrm{M}_{1}\right)\left(\left(-32+230 \mu^{2}-210 \mu^{4}+\right.\right.$

$\left.+15 \mu\left(3-10 \mu^{2}+7 \mu^{4}\right) \log \left[\frac{1+\mu}{1-\mu}\right]\right) \mathrm{F}_{4,1}+$

$\left.+30 \mu\left(3-10 \mu^{2}+7 \mu^{4}\right) \mathrm{L}_{4,1}\right)+\frac{1}{\sqrt{1-\mu^{2}}} 4 \times$

$\times v \rho^{2} \cos [\theta] \cos [\phi]\left(\rho^{9} \mathrm{~A}_{4}+\mathrm{B}_{4}\right) \times$

$\times\left(\sin [\theta] \mathrm{H}_{1}+\cos [\theta] \mathrm{M}_{1}\right)\left(\left(-32+230 \mu^{2}-\right.\right.$

$-210 \mu^{4}+15 \mu\left(3-10 \mu^{2}+7 \mu^{4}\right) \times$

$\left.\times \log \left[\frac{1+\mu}{1-\mu}\right]\right) \mathrm{F}_{4,1}+30 \mu\left(3-10 \mu^{2}+\right.$

$\left.\left.+7 \mu^{4}\right) \mathrm{L}_{4,1}\right)-\frac{1}{-1+\mu^{2}} 12 \rho \cos [\phi] \times$

$\times \sin [\theta]\left(\rho^{11} \mathrm{~A}_{5}+\mathrm{B}_{5}\right)\left(\sin [2 \theta] \mathrm{H}_{2}+\right.$

$\left.+\cos [2 \theta] \mathrm{M}_{2}\right)\left(\left(64-686 \mu^{2}+1260 \mu^{4}-\right.\right.$

$-630 \mu^{6}+105 \mu\left(-1+\mu^{2}\right)^{2}\left(-1+3 \mu^{2}\right) \times$

$\left.\times \log \left[\frac{1+\mu}{1-\mu}\right]\right) \mathrm{F}_{5,2}+210 \mu\left(-1+\mu^{2}\right)^{2} \times$ 


$$
\begin{aligned}
& \left.\times\left(-1+3 \mu^{2}\right) \mathrm{L}_{5,2}\right)+\frac{1}{-1+\mu^{2}} 12 v \rho \times \\
& \times \cos [\phi] \operatorname{Sin}[\theta]\left(\rho^{11} \mathrm{~A}_{5}+\mathrm{B}_{5}\right) \times \\
& \times\left(\sin [2 \theta] \mathrm{H}_{2}+\cos [2 \theta] \mathrm{M}_{2}\right)((64- \\
& -686 \mu^{2}+1260 \mu^{4}-630 \mu^{6}+105 \mu \times \\
& \times\left(-1+\mu^{2}\right)^{2}\left(-1+3 \mu^{2}\right) \log \left[\frac{1+\mu}{1-\mu}\right) \times \\
& \left.\times \mathrm{F}_{5,2}+210 \mu\left(-1+\mu^{2}\right)^{2}\left(-1+3 \mu^{2}\right) \mathrm{L}_{5,2}\right)+ \\
& +\frac{1}{\left(1-\mu^{2}\right)^{3 / 2}} 3 \sin [\phi]\left(\rho^{13} \mathrm{~A}_{6}+\mathrm{B}_{6}\right) \times \\
& \times\left(\sin [3 \theta] \mathrm{H}_{3}+\cos [3 \theta] \mathrm{M}_{3}\right)((-512+ \\
& +7326 \mu^{2}-20286 \mu^{4}+20370 \mu^{6}- \\
& -6930 \mu^{8}+315 \mu\left(-1+\mu^{2}\right)^{3}\left(-3+11 \mu^{2}\right) \times \\
& \times \log \left[\frac{1+\mu_{1}}{1-\mu^{2}}\right) \mathrm{F}_{6,3}+630 \mu\left(-1+\mu^{2}\right)^{3} \times \\
& \left.\left.\times\left(-3+11 \mu^{2}\right) \mathrm{L}_{6,3}\right)\right] .
\end{aligned}
$$

Після визначення переміщення аналогічним методом підстановки знаходяться напруження. Так як вирази для напружень громіздкі, то вони не наводяться.

Далі розглядається спрощена просторова задача НДС тіла за наявності в ньому тріщини. За форму тріщини прийнято еліпсоїд. В такій формі зміною еліптичності можна реалізувати різну степінь кривизни границі тріщини.

За основу досліджень взяті рішення, які запропоновані в [9].

В цьому випадку граничні умови мають наступний вигляд

$$
\sigma_{\mathrm{z}}=-\mathrm{F}, \quad \xi=0, \quad \mathrm{w}=0, \quad \mathrm{c}=0,
$$

де $\xi=$ const - сімейство еліпсоїдів; с - гіперболоїди з одною порожниною; w - переміщення в напрямку осі $\mathrm{z} ; \sigma_{z}$ - напруження в напрямку осі z.

Переміщення від дії нормальних зусиль через еліптичні координати будуть мати наступний вигляд:

$$
u_{n}=\frac{2 A x}{a b^{2}}\left[( 1 - 2 v ) \left[u_{f}+E\left[u_{f}\right] \times\right.\right.
$$

$$
\begin{aligned}
& \mathrm{v}_{\mathrm{n}}=\frac{2 \mathrm{Ay}}{\mathrm{ab}^{2}}\left[( 1 - 2 v ) \left[\mathrm{E}\left[\mathrm{u}_{\mathrm{f}}\right]-\mathrm{m}^{2} \mathrm{u}_{\mathrm{f}}-\right.\right. \\
& \left.-\mathrm{m}^{2} \frac{\mathrm{sn}\left[\mathrm{u}_{\mathrm{f}}\right] \times \mathrm{cn}\left[\mathrm{u}_{\mathrm{f}}\right]}{\operatorname{dn}\left[\mathrm{u}_{\mathrm{f}}\right]}\right] \frac{1}{\mathrm{~m}^{2}}- \\
& \left.-\frac{\mathrm{bz}\left[\left(\mathrm{a}^{2}+\xi\right) \mathrm{c} \vartheta\right]^{1 / 2}}{(\xi-\mathrm{c})(\xi-\vartheta)\left(\mathrm{b}^{2}+\xi\right)^{1 / 2}}\right] \\
& \mathrm{w}_{\mathrm{n}}=\frac{2 \mathrm{Az}}{\mathrm{ab}^{2}}\left[(1-2 \mathrm{v}) \mathrm{E}\left[\mathrm{u}_{\mathrm{f}}\right]+\right. \\
& +\left[\frac{\operatorname{cn}\left[u_{f}\right]}{\operatorname{dn}\left[u_{f}\right]}-2(1-v) \frac{d n\left[u_{f}\right]}{\operatorname{cn}\left[u_{f}\right]}\right] \operatorname{sn}\left[u_{f}\right]+ \\
& +\frac{\xi^{1 / 2}}{a(\xi-\rangle)(\xi-\vartheta)\left(a^{2}+\xi\right)^{1 / 2}\left(b^{2}+\xi\right)^{1 / 2}} \times \\
& \times\left[\xi\left(\mathrm{a}^{2} \mathrm{~b}^{2}-\mathrm{c} \vartheta\right)-\mathrm{a}^{2} \mathrm{~b}^{2}(\mathrm{c}+\vartheta)-\right. \\
& \left.\left.-\left(a^{2}+b^{2}\right) c \vartheta\right]\right] \text {. }
\end{aligned}
$$

де $\vartheta$ - гіперболоїди 3 двома порожнинами; $\mathrm{E}\left[\mathrm{u}_{\mathrm{f}}\right]=\int_{0}^{\mathrm{u}_{\mathrm{f}}} \mathrm{dn}^{2} \beta \mathrm{d} \beta-$ функція; $\mathrm{u}_{\mathrm{f}}-$ змінний параметр; m'- аргумент еліптичної функції (модуль інтеграла), $\left(\mathrm{m}^{\prime}\right)^{2}+(\mathrm{m})^{2}=1 ; \operatorname{sn}\left[\mathrm{u}_{\mathrm{f}}\right], \mathrm{cn}\left[\mathrm{u}_{\mathrm{f}}\right], \mathrm{dn}\left[\mathrm{u}_{\mathrm{f}}\right]-$ еліптичні функції Якобі; a, b - відповідно велика і мала напіввісі еліпсу [11].

Стала А знаходимо за наступною залежністю

$$
A=-\frac{a b^{2} F}{4 \mu E(m)}
$$

де $\mathrm{E}(\mathrm{m})=\int_{0}^{\frac{\pi}{2}} \sqrt{1-\mathrm{k}^{2}(\sin [\varphi])^{2}} \mathrm{~d} \varphi-$ повний еліптичний інтеграл другого роду; $\varphi$ - амплітуда інтеграла, $\mathrm{m}=\sin [\alpha]-$ модуль інтеграла; $\alpha$ - модулярний кут [10].

Так як переміщення, зазначені в формулах (8) - (10), були визначені для еліптичних координат, а попередні розрахунки виконані для сферичної системи, то при виконанні подальших розрахунків було потрібно перейти до єдиної системи координат. 
Прийнято як більш зручнішу сферичну систему координат.

Формули для переводу еліптичних координат в декартові та декартових координат в сферичні наведені в [4].

Переміщення в сферичних координатах мають наступний вигляд:

$$
\begin{aligned}
& u_{n}=\frac{A}{3 r^{7}}\left(21 r^{5}-70 r^{4} \rho+105 r^{3} \rho^{2}-\right. \\
& \left.-84 r^{2} \rho^{3}+35 r \rho^{4}-6 \rho^{5}\right)(-3+(-5+4 v) \times \\
& \times \cos [2 \phi])+O[\rho-r]^{6} ; \\
& v_{n}=0 ; \\
& w_{n}=-\frac{2 A}{3 r^{7}} \times(-1+2 v)\left(21 r^{5}-70 r^{4} \rho+\right. \\
& \left.+105 r^{3} \rho^{2}-84 r^{2} \rho^{3}+35 r \rho^{4}-6 \rho^{5}\right) \times \\
& \times \sin [2 \phi]+O[\rho-r]^{6} .
\end{aligned}
$$

Після підстановки рівнянь (12 - 14) в рівняння для визначення напружень (5 - 7), (12) отримано наступні залежності:

$$
\begin{aligned}
& \sigma_{\rho \rho}=\frac{1}{3 r^{7}} 2 \mathrm{~A}\left(\mathrm { G } \left(-70 \mathrm{r}^{4}+210 \mathrm{r}^{3} \rho-\right.\right. \\
& \left.-252 \mathrm{r}^{2} \rho^{2}+140 \mathrm{r} \rho^{3}-30 \rho^{4}\right)(-3+ \\
& +(-5+4 v) \operatorname{Cos}[2 \phi])-1 / \rho \lambda\left(42 \mathrm{r}^{5} \times\right. \\
& \times(1+v)-35 \mathrm{r}^{4}(7+4 v) \rho+105 \mathrm{r}^{3} \times \\
& \times(5+2 v) \rho^{2}-42 \mathrm{r}^{2}(13+4 v) \rho^{3}+ \\
& +70 \mathrm{r}(4+v) \rho^{4}-3(19+4 v) \rho^{5}+ \\
& +3\left(14 \mathrm{r}^{5}(1+v)-105 \mathrm{r}^{4} \rho-35 \mathrm{r}^{3} \times\right. \\
& \times(-7+2 v) \rho^{2}+14 \mathrm{r}^{2}(-19+8 v) \times \\
& \times \rho^{3}-70 \mathrm{r}(-2+v) \rho^{4}+(-29+16 v) \times \\
& \left.\left.\left.\times \rho^{5}\right) \operatorname{Cos}[2 \phi]\right)\right) ; \\
& \sigma_{\theta \theta}=\frac{1}{3 r^{7} \rho} 2 \mathrm{~A}\left(-\mathrm{G}\left(21 \mathrm{r}^{5}-70 \mathrm{r}^{4} \rho+\right.\right. \\
& \left.+105 \mathrm{r}^{3} \rho^{2}-84 \mathrm{r}^{2} \rho^{3}+35 r \rho^{4}-6 \rho^{5}\right) \times \\
& \times(1+4 v+3 \operatorname{Cos}[2 \phi])-\lambda\left(42 \mathrm{r}^{5} \times\right. \\
& \times(1+v)-35 \mathrm{r}^{4}(7+4 v) \rho+105 \mathrm{r}^{3} \times \\
& \times(5+2 v) \rho^{2}-42 \mathrm{r}^{2}(13+4 v) \rho^{3}+ \\
& +70 \mathrm{r}(4+v) \rho^{4}-3(19+4 v) \rho^{5}+ \\
& +3\left(14 \mathrm{r}^{5}(1+v)-105 r^{4} \rho-35 r^{3} \times\right. \\
& \times(-7+2 v) \rho^{2}+14 r^{2}(-19+8 v) \rho^{3}- \\
& \left.-70 \mathrm{r}(-2+v) \rho^{4}+(-29+16 v) \rho^{5}\right) \times
\end{aligned}
$$

$\times \operatorname{Cos}[2 \phi]))$;

$$
\begin{aligned}
& \sigma_{\phi \phi}=-\frac{1}{3 r^{7} \rho} 2 \mathrm{~A}\left(3 \mathrm { G } \left(21 \mathrm{r}^{5}-70 \mathrm{r}^{4} \rho+\right.\right. \\
& \left.+105 \mathrm{r}^{3} \rho^{2}-84 \mathrm{r}^{2} \rho^{3}+35 r \rho^{4}-6 \rho^{5}\right)+ \\
& +\lambda\left(42 \mathrm{r}^{5} \times(1+v)-35 \mathrm{r}^{4}(7+4 v) \rho+\right. \\
& +105 \mathrm{r}^{3}(5+2 v) \rho^{2}-42 \mathrm{r}^{2}(13+4 v) \times \\
& \left.\times \rho^{3}+70 \mathrm{r}(4+v) \rho^{4}-3(19+4 v) \rho^{5}\right)+ \\
& +\left(G ( 1 + 4 v ) \left(21 r^{5}-70 \mathrm{r}^{4} \rho+105 \mathrm{r}^{3} \rho^{2}-\right.\right. \\
& \left.-84 r^{2} \rho^{3}+35 r \rho^{4}-6 \rho^{5}\right)+3 \lambda\left(14 r^{5}(1+\right. \\
& -v)-105 r^{4} \rho-35 r^{3}(-7+2 v) \times \rho^{2}+ \\
& +14 r^{2}(-19+8 v) \rho^{3}-70 r(-2+v) \times \\
& \left.\left.\left.\times \rho^{4}+(-29+16 v) \rho^{5}\right)\right) \cos [2 \phi]\right) ; \\
& \tau_{\rho \theta}=0 ;
\end{aligned}
$$

$$
\begin{gathered}
\tau_{\rho \phi}=-\frac{4 A G}{3 r^{7} \rho}\left(21 r^{5}(-2+v)-35 r^{4} \times\right. \\
\times(-5+4 v) \rho+315 r^{3}(-1+v) \rho^{2}- \\
-42 r^{2}(-7+8 v) \rho^{3}+35 r \times(-4+5 \times \\
\left.\times v) \rho^{4}+9(3-4 v) \rho^{5}\right) \operatorname{Sin}[2 \phi] . \\
\tau_{\theta \phi}=0 .
\end{gathered}
$$

Таким чином, знаючи всі складові напружень та переміщень для двох напружено-деформованих станів, можливо розрахувати їхні сумарні значення та визначити сумарну енергію руйнування за наявності в тілі тріщини.

Аналіз виразів (15) - (20), дозволяє зробити висновок, що напруження, які виникають в тілі з тріщиною, залежать в цілому від наступних величин: $a, b, F, r, m$.

За умови, що параметри $b, F, r$ задані, побудовано графіки залежності головних напружень від розміру більшої напіввісі еліпса тріщини (рис.3). Головні напруження на поверхні тіла в заданій точці прикладення зусиль знайдено з рівнянь граничних умов на контурі. 


\section{АОСАІАЖЕННЯ ПРОЦЕСУ РУЙНУВАННЯ МАТЕРІААУ В КАМЕРІ АРОБАЕННЯ ВІБРАЦІЙНОЇ ЩОКОВОЇ АРОБАРКИ}

Графік залежності напружень від радіусу $\mathrm{r}$ зображений на рис.4. Параметри $a, b, F, m$, $\varphi, \theta$ були прийняті сталими.

Вплив еліптичного модуля на напруження зображений на рис.5

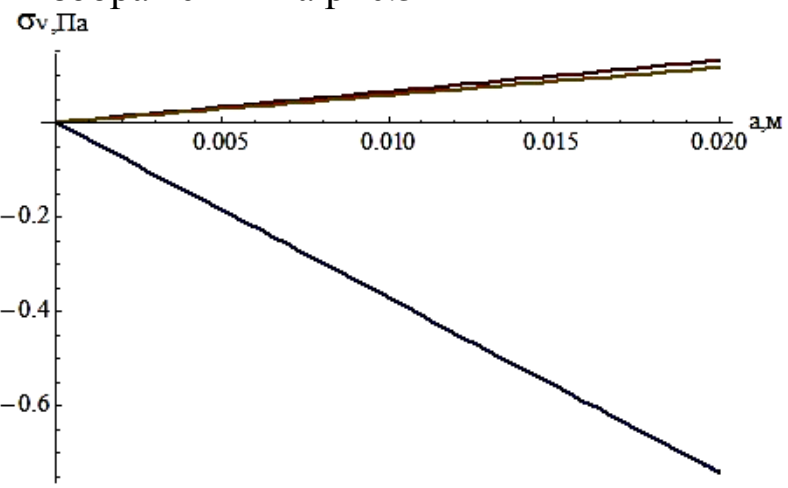

Рис.3. Графік залежності напружень від розміру більшої напіввісі еліпса

Fig.3. Graph of dependencies of the stress on the size of the ellipse axis more

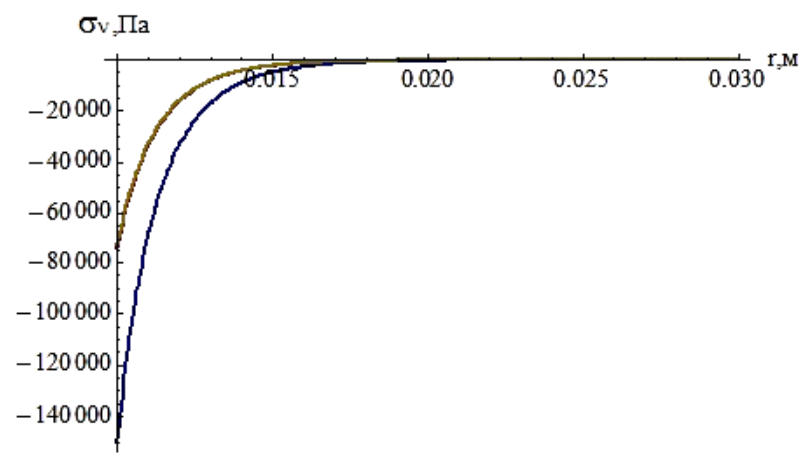

Рис.4. Графік розподілу напружень в залежності від віддалення від тріщини

Fig.4. Graph of dependencies of the stress on the distance from the crack

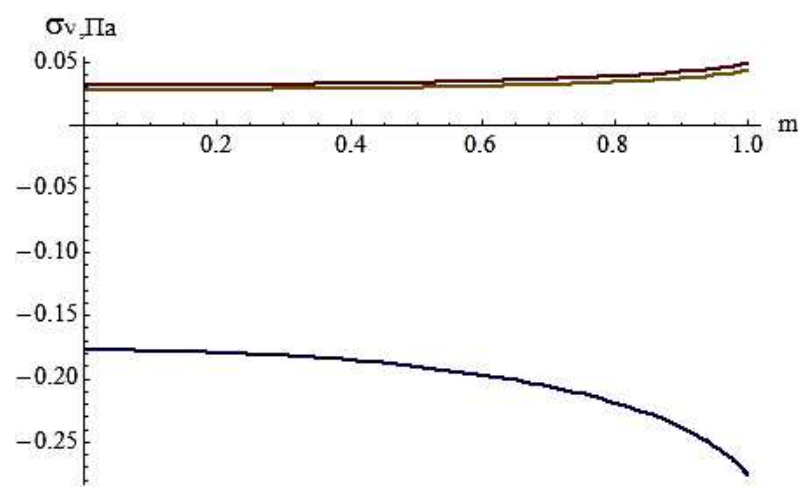

Рис.5. Графік залежності напружень на поверхні тіла 3 тріщиною від еліптичного модуля

Fig.5. Graph of dependencies of the stress on the body surface from cracking elliptic module

\section{ВИСНОВКИ}

При збільшенні розміру більшої напіввісі еліпса в тілі виникають напруження, які значно менші напружень в тілі без тріщини.

Напруження біля краю тріщини необмежено зростають. Проте внаслідок різноспрямованості напружень по всій довжині в околі границі тріщини загальні напруження тіла $з$ тріщиною будуть мати невеликі значення.

При збільшенні еліптичного модуля зростання напружень $є$ незначним.

Основна частина енергії при руйнуванні матеріалу йде на пружну деформацію та утворення тріщини, а енергія тіла після утворення тріщина $є$ набагато меншою.

Врахування при визначенні енергетичних витрат на руйнування напруженодеформованого стану матеріалу дає можливість задати оптимальні режими роботи дробарки.

Знання дійсних енергетичних витрат на руйнування матеріалу створює передумови до створення енергоефективних дробильних машин. Розраховані значення зусиль руйнування були співставленні із значеннями зусиль руйнування, визначеними дослідним шляхом. Відмінність результатів $\epsilon$ незначною.

\section{ЛІТЕРАТУРА}

1. Perelman $G$. The entropy formula for the Ricci flow and its geometric applications/ Perelman G.// arXiv:math/0211159v1 [math.DG]. 2002. - $39 \mathrm{c}$.

2. Perelman $G$. Ricci flow with surgery on threemanifolds/ Perelman G.// arXiv:math/0303109v1 [math.DG]. - 2003. $22 \mathrm{c}$.

3. Perelman $G$. Finite extinction time for the solutions to the Ricci flow on certain threemanifolds/ Perelman G.// arXiv:math/0307245v1 [math.DG]. - 2003. - 7 c.

4. Либовии Г. Разрушение. Т.2. Математические основы теории разрушения. М.: Мир, 1975. 
5. Можаровський М.С. Теорія пружності, пластичності і повзучості: Підручник. - К.: Вища шк., 2002. - 308 с.: іл.

6. Хан $X$. Теория упругости: Основы линейной теории и ее применения: Пер. с нем. - М.: Мир, 1988. - 344 с., ил.

7. Безухов Н.И. Основы теории упругости, пластичности, ползучести. М., «Высшая школа», 1968.

8. Рекач В.Г. Руководство к решению задач по теории упругости. М.: Высшая школа, 1966. $-229 \mathrm{c}$.

9. Green A.E., Sneddon I.N., Proc. Cambridge Philos. Soc., 46 (1950), 159.

10. Журавский А.М. Справочник по эллиптическим функциям. Издательство Академия наук Союза ССР, Москва 1941 г.

11. Абрамовии М., Стиган И. Справочник по специальным функциям с формулами, графиками и математическими таблицами. М.: Наука, 1979. 832 с.

12. С.П.Тимоченко, Дж.Гудьер. Теория упругости, перев. с англ. Главная редакция физико-математической литературы изд-ва «Наука». 1975 г., стр. 576.

13. В.С.Блохин,В.И.Большаков,Н.Г.Малич. Основные параметры технологических машин. Машины для дезинтеграции твердых материалов: Учебное пособие. ч.І. - Днепропетровск: ИМА-пресс. - 2006. - $404 \mathrm{c.}$

14. Назаренко I.I. Аналіз і оцінка енергетичних характеристик дробарок $з$ керованими параметрами. / I.I. Назаренко, Є.О. Міщук // Науково-технічний журнал «Гірничі, будівельні, дорожні та меліоративні машини»: зб. наук. пр. - К.: № 75, 2010. - 19-24 с.

15. Назаренко I.I. Оцінка енергоємності процесу подрібнення будівельних матеріалів/ I.I. Назаренко, Є.О. Міщук // Техніка будівництва. - 2012. - №28. - с. 20-29.

16. Галеркин Б.Г. Общее решение уравнений теории упругости для ізотропного тела. «ДАН СССР», сер. А, 1930, стр. 355.

17. Neuber G. Ein neuer Ansatz zur Lösung räumlicher Probleme der Elastizitätstheorie. Zeitschr, für angew. Math. Und Mech., 14, 1934, №34.

18. Треффи E. «Прикл. матем. и механ.», т.10, вып. 4, 1946.

19. Sneddon I.N., Proc. Roy. Soc. London, Ser. A, 187 (1946), 229.

20. Sack R.A., Proceedings of the Physical Society. Vol. 58, (London), 1946, 729.

21. Segedin C. M., Proc. Cambridge Philos. Soc., 47 (1950), 396.
22. Треффи E., Матиматическая теория упругости, ОНТИ, Л. - М., 1934.

23. Лурье А.И., Теория упругости, М., 1970 г., $940 \mathrm{c}$.

\section{REFERENCES}

1. Perelman G., 2002. The entropy formula for the Ricci flow and its geometric applications. arXiv:math.0211159v1 [math.DG]., 1-39.

2. Perelman G., 2003. Ricci flow with surgery on three-manifolds. arXiv:math.0303109v1 [math.DG]., 1-22.

3. Perelman G., 2003. Finite extinction time for the solutions to the Ricci flow on certain threemanifolds. arXiv:math.0307245v1 [math.DG]., 1-7.

4. Libovic G., 1975. Razrushenie. T.2. Matematicheskie osnovy teorii razrushenija [Mathematical foundations of the theory of fracture]. Moscow, Mir Publ., 763.

5. Mozharovs'kij M.S., 2002. Teorija pruzhnosti, plastichnosti i povzuchosti: Pidruchnik [Theory of elasticity, plasticity, and creep: The textbook]. Kyiv, Vishha shk.Publ., 308.

6. Han H., 1988. Teorija uprugosti: Osnovy linejnoj teorii i ee primenenija: Per. $s$ nem [Elasticity Theory: Fundamentals of linear theory and its applications: Trans. from Ger]. Moscow, Mir Publ., 344.

7. Bezuhov N.I., 1968. Osnovi teorii uprugosti, plastichnosti, polzuchesti [Fundamentals of the theory of elasticity, plasticity, creep]. Moscow, Vysshaja shkola, 512.

8. Rekach V.G., 1966. Rukovodstvo k resheniju zadach po teorii uprugosti [Guide to solving problems in the theory of elasticity]. Moscow, Vysshaja shkola, 229.

9. Green A.E., Sneddon I.N., 1950. Proc. Cambridge Philos. Soc., 46, 159.

10. Zhuravskij A.M., 1941. Spravochnik po jellipticheskim funkcijam [Handbook of elliptic functions]. Izdatel'stvo Akademija nauk Sojuza SSR, Moscow, 235.

11. Abramovic M., Stigan I., 1979. Spravochnik po special'nym funkcijam s formulami, grafikami i matematicheskimi tablicami [Directory functions with formulas, graphs, and mathematical tables]. Moscow, Nauka, 832.

12. Timoshenko S.P., Gud'er Dzh., 1975. Teorija uprugosti, perev. $\mathrm{s}$ angl [Elasticity theory, Trans. from English]. Glavnaja redakcija fiziko-matematicheskoj literatury izd-va Nauka., 576.

13. Blohin V.S., Bol'shakov V.I., Malich N.G., 2006. Osnovnye parametry tehnologicheskih 


\section{АОСАІАЖЕННЯ ПРОЦЕСУ РУЙНУВАННЯ МАТЕРІААУ В КАМЕРІ АРОБАЕННЯ ВІБРАЦІЙНОЇ ЩОКОВОЇ АРОБАРКИ}

mashin. Mashiny dlja dezintegracii tverdyh materialov: Uchebnoe posobie [Basic parameters of technological machines. Machines for the disintegration of solid materials: Textbook]. ch.I. Dnepropetrovsk: IMA-press., 404.

14. Nazarenko I.I., Mishchuk E.O., 2010. Analiz i ocinka energeti-chnih harakteristik drobarok z kerovanimi parametrami [Analysis and evaluation of energy characteristics of crushers with controlled parameters]. Girnichi, budivel'ni, dorozhni ta meliorativni mashini [Mining, construction, road and meliorative machines], Vol. 75, 19-24. (in Ukrainian)

15. Nazarenko I.I., Mishchuk E.O., 2012. Ocinka energocmnosti procesu podribnennja budivel'nih materialiv [Evaluation of energy intensity crushing process of building materials. Tehnika budivnictva [The technics of construction], Vol. 28, 20-29. (in Ukrainian)

16. Galerkin B.G., $1930 . \quad$ Obshhee reshenie uravnenij teorii uprugosti dlja izotropnogo tela
[The general solution of the equations of the theory of elasticity for an isotropic body]. «DAN SSSR», ser. A, 355.

17. Neuber G., 1934. Ein neuer Ansatz zur Lösung räumlicher Probleme der Elastizitätstheorie. Zeitschr, für angew. Math. Und Mech., 14, Vol.34.

18. Treffc E., 1946. «Prikl. matem. i mehan.» [Applied Mathematics and Mechanics], Vol.10, no. 4.

19. Sneddon I.N., 1946. Proc. Roy. Soc. London, Ser. A, 187, 229.

20. Sack R.A., 1946. Proceedings of the Physical Society Vol. 58, London, 729.

21. Segedin C. M., 1950. Proc. Cambridge Philos. Soc., 47, 396.

22. Treffc E., 1934. Matimaticheskaja teorija uprugosti [Mathematical theory of elasticity], ONTI, L, Moscow.

23. Lur'e A.I., 1970. Teorija uprugosti [Theory of elasticity], Moscow, 940. 
